\title{
Designing an Effective Combined Shewhart-CUSUM Control Scheme with Exponentially Distributed Data
}

\author{
Dushyant Tyagi \\ Department of Mathematics and Statistics \\ Dr. Shakuntala Misra National Rehabilitation University \\ Lucknow-226017, India \\ E-mail: dtyagi@dsmnru.ac.in
}

(Received May 13, 2019; Accepted July 24, 2019)

\begin{abstract}
In this paper, the Combined Shewhart-CUSUM control scheme has been proposed to monitor the production process when the quality characteristic follows exponential distribution to quickly detect the shift in the process. The simulated values of ARL are determined after the transformation of the data into approximate normal distribution by Nelson transformation method and adding Shewhart control limits to existing CUSUM Control Chart. Scheme parameters (value of $\mathrm{k}$ and $\mathrm{h}$ ) and out of control ARL are calculated at various shift and at various in-control ARL. Parameters are also calculated to detect $\delta$ standard deviation shifts, which may be helpful to the quality control practitioners in designing the Combined Shewhart-CUSUM scheme when data is highly skewed.
\end{abstract}

Keywords- Combined Shewhart-CUSUM scheme, Exponential distribution, Average runs length, Monte Carlo simulation.

\section{Introduction}

Statistical process control is the widely used technique for controlling the quality in manufacturing and service industry. Initially Statistical Process Control (SPC) was developed by Walter Andrew Shewhart in 1924. Shewhart puts the foundation for the control chart to check that the process is statistically controlled or not. It is noted that Shewhart (3 sigma) control chart for the mean is very useful if the shift in process parameters magnitude is 1.5 sigma or larger (Montgomery, 2018), but takes a large number of runs to detect a small constant shift in the process quality characteristic. In SPC, many times a quality control engineer concerned to monitor the occurrence of events that can occur at any point within a continuous interval of time. For example, the number of false alarm per day, wrong number connection per day or product replacement calls in a given period of time. If such events occur "uniformly at random," the number of occurrences per unit time leads to the Poisson distribution. The traditional approach for monitoring Poisson counts is based on the Shewhart control chart called c chart. However, many researchers like Nelson (1994), Gan (1994) have discovered that the c chart is inadequate for controlling highly efficient processes. For highly efficient processes, numbers of occurrences are very lesser. Its result that most of the sample observations for $\mathrm{c}$ chart applications will have zero value. Hence, c charts will be a plot of a series of zeros with some rare nonzero observation. Really, under such situations, the Shewhart c chart becomes quite ineffective for process control. To overcome this problem with the c chart (Nelson, 1994) proposed to monitor these types of processes by different measurements, that is, the time between successive occurrences of the events and this random variable follows the exponential distribution. Due to asymmetric shape, the exponential distribution violates the normality assumption of Shewhart chart, therefore, the use of normal-based Shewhart control chart for the time between occurrences would not be relevant and cause of misleading interpretation of data, a wrong process diagnosis or an 
International Journal of Mathematical, Engineering and Management Sciences

Vol. 4, No. 5, 1277-1286, 2019

https://dx.doi.org/10.33889/IJMEMS.2019.4.5-101

inappropriate SPC chart can generate disastrous accidents. To overcome this problem, Nelson (1994) suggested a method to transform exponential random variable into approximate normal so normal-based Shewhart control limits can be used to monitor the time between occurs.

Page (1954) developed a Cumulative Sum (CUSUM) control chart to detect the small shift in the process in which information from past observations is also included to take the decision at any stage of the process that means Cumulative sum of deviation from target value is plotted against the sample number. Lucas and Crosier (1982), Lucas (1985), Duncan (1986), Hawkins (1992) also showed that CUSUM control chart is moreover efficient than the traditional Shewhart's control chart for detecting a small shift in the average. Chan et al. (2000) had proposed CQC chart to monitor the time between events (TBE) data that are exponentially distributed. Lucas (1985), Vardeman and Ray (1985), Alwan (2000) had proposed the exponential CUSUM chart. Kittlitz (1999) used a double square root (SQRT) transformation method for developing I-chart, exponentially weighted moving average (EWMA) and CUSUM chart. Montgomery (2018) stated that "in many cases, the CUSUM and EWMA control charts would be better alternatives because these charts are more effective in detecting small shifts in mean". Liu et al. (2006), Tyagi (2013) proposed the optimal design of the CUSUM Chart with transformed exponential distributed data and determined the average run length (ARL) properties of the proposed chart. Lucas (1982) proposed combined Shewhart-CUSUM Quality control schemes for normally distributed data and shows that its performance is better to detect a large shift in compare to the CUSUM chart. In this study, we propose a combined Shewhart-CUSUM scheme for transformed exponentially distributed data.

In this paper, a combined Shewhart-CUSUM control scheme is proposed to observe a set of exponentially distributed data after transformation to quickly detect the shift in the mean. A transformation method suggested by Nelson is used to transform exponentially distributed data to approx. normal. The ARL for the proposed scheme is calculated by simulation technique. A comparative study on the ARL is also conducted. CUSUM control charts are represented by two ways, the tabular or algorithmic CUSUM and the V- mask CUSUM. Here, we consider the tabular CUSUM as it is more preferred by the practitioners.

The break-up of the paper is ordered as follows. In Section 2, the transformation of exponentially distributed data is discussed. In Section 3, parameters for the combined Shewhart-CUSUM scheme are determined. In Section 4, a numerical example has been given for highlighting the use of the theoretical developments. In Section 5, ARL values are determined to compare shift detection properties of the proposed Combined Shewhart-CUSUM scheme. Finally, Section 6 concludes the work by discussing the results.

\section{Transformation of Exponentially Distributed Variable}

A popular distribution for modeling lifetime is Weibull distribution $\mathrm{W}(\lambda, \mathrm{k})$, has a density function:

$f(x, \lambda, k)= \begin{cases}\frac{k}{\lambda}\left(\frac{x}{\lambda}\right)^{k-1} e^{-(x / \lambda)^{k},} & x \geq 0 \\ 0, & x<0\end{cases}$

where $\lambda>0$ is the scale parameter and $\mathrm{k}>0$ is the shape parameter. 
International Journal of Mathematical, Engineering and Management Sciences

Vol. 4, No. 5, 1277-1286, 2019

https://dx.doi.org/10.33889/IJMEMS.2019.4.5-101

The mean and variance of $\mathrm{X}$ is

$\mu_{\mathrm{x}}=\lambda \cdot \Gamma\left(1+\frac{1}{\mathrm{k}}\right)$

$\operatorname{Var}(\mathrm{X})=\lambda^{2}\left[\Gamma\left(1+\frac{2}{\mathrm{k}}\right)-\left(\Gamma\left(1+\frac{1}{\mathrm{k}}\right)\right)^{2}\right]$

Where $\Gamma($.$) is the complete gamma function.$

As we know that exponential distribution is a particular case of Weibull distribution. i.e when shape parameter $\mathrm{k}=1$, Weibull distribution is known as exponential distribution. So with the help of equation (2) and (3) mean and standard deviation for the exponential distribution can be calculated.

An important fact used in this paper is that if $X$ follows Weibull distribution with shape parameter $\mathrm{K}$ and scale parameter $\lambda$, then another variable obtained by $\mathrm{Y}=\mathrm{X}^{\mathrm{p}}$ (with $\mathrm{p}>0$ ) follows $\mathrm{W}\left(\lambda^{\mathrm{p}}, \mathrm{k} /\right.$ p). Hence the distribution of an exponential random variable $W(\lambda, 1)$ raised to the power $p$ follows $\mathrm{W}\left(\lambda^{\mathrm{p}}, 1 / \mathrm{p}\right)$. According to Nelson (1994) for any $\alpha>0, \mathrm{~W}(\alpha, 3.6)$ has zero skewness value and approximate three kurtosis value i.e. follows approximate normal distribution. Since $(1 / 0.27777)$ is nearly equal to 3.6. So we can easily say that putting the power $p=0.27777$ on exponential distributed random variable. i.e. $\mathrm{W}\left(\lambda^{0.27777}, 3.6\right)$, follows an approximately normal distribution.

From equation (2) and (3), the mean and standard deviation of transformed variable say, ' $\mathrm{Y}$ ' are

$$
\begin{aligned}
\mu_{Y} & =\lambda^{0.27777} \cdot \Gamma\left(1+\frac{1}{3.6}\right) \\
& =0.9011057 \lambda^{0.27777} \\
\Sigma_{Y} & =\lambda^{0.27777} \sqrt{\left[\Gamma\left(1+\frac{2}{3.6}\right)-\left(\Gamma\left(1+\frac{1}{3.6}\right)\right)^{2}\right]} \\
& =0.2780203 \lambda^{0.27777}
\end{aligned}
$$

\section{Combined Shewhart-CUSUM Scheme for Controlling the Process Mean}

For the CUSUM chart, when the process is under control, Let random variable $\mathrm{Y}$ follow a normal distribution with mean $\mu_{\mathrm{y} 0}$ and standard deviation $\sigma$ (known or estimable), $\mu_{\mathrm{y} 0}$ is assumed to be the standard value for the quality characteristic Y. The tabular CUSUM works by plotting the cumulative sum of the deviations of observation from $\mu_{\mathrm{y} 0}$ after subtracting the reference value. Two statistic is calculated, one statistic $\mathrm{C}+$ for the deviation in the upper side of the standard value and another statistic $\mathrm{C}$ - for the deviation in the lower side of the standard value. Where $\mathrm{C}+$ and C-statistic is calculated as

$$
\begin{aligned}
& C_{i}^{+}=\max \left[0, \mathrm{y}_{\mathrm{i}}-\left(\mu_{\mathrm{y} 0}+\mathrm{k} \sigma_{y}\right)+C_{i-1}^{+}\right] \\
& \mathrm{C}_{\mathrm{i}}-=\min \left[0, \mathrm{y}_{\mathrm{i}}-\left(\mu_{\mathrm{y} 0}-\mathrm{k} \sigma_{\mathrm{y}}\right)+\mathrm{C}_{\mathrm{i}-1}-\right]
\end{aligned}
$$


International Journal of Mathematical, Engineering and Management Sciences

Vol. 4, No. 5, 1277-1286, 2019

https://dx.doi.org/10.33889/IJMEMS.2019.4.5-101

where $y_{i}$ is the $i^{\text {th }}$ transformed observation of the process.

With the starting value $C_{i}^{+}=C_{i}^{-}=0$. Where $\mathrm{k}=\delta / 2$, is called the reference or allowable value where $\delta$ is the smallest shift, the researcher wants to detect, measured in units of process standard deviation. Thus,

$\mathrm{k}=\frac{\left|\mu_{\mathrm{y} 1}-\mu_{\mathrm{yo}}\right|}{2 \sigma_{y}}$

The cumulative statistic values $C_{i}^{+}$and $C_{i}^{-}$are the cumulative sum of deviation from the standard value $\mu_{\mathrm{y} 0}$ that is greater than $\mathrm{k} \sigma_{y}$. If any of the two statistic crossed the decision interval $\mathrm{H}$, the process is said to be out of control. Here $\mathrm{H}=\mathrm{h} \sigma_{y}$ is known as the decision interval of the CUSUM chart (Montgomery, 2018).

A number of authors have used different methods to determine the value of $\mathrm{h}$ and $\mathrm{k}$ by using incontrol ARL of the CUSUM chart. Woodall and Adams (1993) recommended approximation method based on specified in-control ARL given by Siegmund (1985) to develop an iterative procedure for determining the value of $\mathrm{h}$ for a known value of $\mathrm{k}$ when applying a two-sided procedure.

$h_{n}=h_{n-1}-\frac{e^{2 k\left(h_{n-1}+1.166\right)}-2 k\left(h_{n-1}+1.166\right)-1-2 k^{2} A R L_{0}}{2 \mathrm{ke}^{2 k\left(h_{n-1}+1.166\right)}-2 k}$

with $\mathrm{n}=1,2,3, \ldots, \mathrm{ARL}_{0}$ is the specified in-control $\mathrm{ARL}$, and $\mathrm{h}_{0}$ is any positive initial value. As the iterations move on, $h_{n}$ will reach to the desired $h$ value which constructs CUSUM control chart whose true in-control ARL approximates equal to the desired ARL $\mathrm{L}_{0}$ value. Woodall and Adams (1993) recommend to continue the iteration until the difference between two consecutive $h$ values is more than 0.005 (that is, $\left|h_{n}-h_{n-1}\right|<0.005$ ) and then take the $h$ value to the second decimal place.

Let us study a particular case. Suppose the quality characteristic follows an exponential distribution with target mean $\mu_{0}$. If the quality control engineer wants to detect a shift in the lower side, then the value should be suggested ' $\mu_{1}-$ ', which is the mean value that one wishes to detect as soon as possible. If the requirement is to detect shift in the upper side, then a value should be suggested ' $\mu_{1}+$ ', which is the mean value that one wishes to detect as soon as possible. Let $\mathrm{x}_{1}, \mathrm{x}_{2}$, $\ldots \ldots, \mathrm{x}_{\mathrm{n}}$, is a sequence of exponentially distributed process observations, so equations 6 - 9 can be used to determine the parameters of the CUSUM chart as follows:

$$
\begin{aligned}
& k=\frac{\left|0.9011057 \lambda_{1}^{0.27777}-0.9011057 \lambda_{0}{ }^{0.27777}\right|}{2 * 0.2780203 \lambda_{0}{ }^{0.27777}} \\
& C_{i}+=\max \left[0, x_{i}^{0.27777}-\left(0.9011057 \lambda_{0}^{0.27777}+k * 0.2780203 \lambda_{0}^{0.27777}\right)+C_{i-1}+\right] \\
& C_{i}-=\min \left[0, x_{i}^{0.27777}-\left(0.9011057 \lambda_{0}^{0.27777}-k * 0.2780203 \lambda_{0}^{0.27777}\right)+C_{i-1}-\right]
\end{aligned}
$$


International Journal of Mathematical, Engineering and Management Sciences

Vol. 4, No. 5, 1277-1286, 2019

https://dx.doi.org/10.33889/IJMEMS.2019.4.5-101

For the upper one-sided CUSUM control chart detect the shift if $C_{i}+>h \sigma_{y}$ whereas for the lower one-sided CUSUM control chart detect the lower side shift if $C_{i}-<-h \sigma_{y}$.

The Combined Shewhart-CUSUM scheme adds one more condition that if $\mathrm{y}_{\mathrm{i}}$ (transformed value of observation) > Shewhart Control Limit Upper (SCLU) or $y_{i}<$ Shewhart Control Limit Lower (SCLL), chart signals out of control situation. Additional Shewhart control limit modifies the standard CUSUM chart to quickly detect large shifts of the mean from the target value.

\section{Example}

Suppose the quality under consideration follows exponential distribution. A sample of 100 observations is generated in which first 70 observation were drawn at random from exponential distribution with mean time between failure $=1$. The last 30 observations were drawn from the exponential distribution with mean time between failure $=2$, shown in Table 1 . Thus, we can say that the last 30 observations have been drawn from the out of control process. That is after the process mean is shifted by 1 point. By the method described in this paper with a pre-specified incontrol ARL of 250, parameters can be determined as below:

Reference value ' $k$ ' is given by equation (10) i.e.

$$
\begin{aligned}
& k=\frac{\left|0.9011057 *(2)^{0.27777}-0.9011057 *(1)^{0.27777}\right|}{2 * 0.2780203 * 1^{0.27777}} \\
& \mathrm{k}=0.3440894
\end{aligned}
$$

By equation (9) we calculate value of ' $h$ ', starting with $h_{0}=10$ along with $A_{R L}=250$ and $k=$ 0.3440894 as:

$$
\begin{aligned}
\mathrm{h}_{1} & =\mathrm{h}_{0}-\frac{\mathrm{e}^{2 * 0.3440894\left(\mathrm{~h}_{0}+1.166\right)}-2 * 0.3440894\left(\mathrm{~h}_{0}+1.166\right)-1-2 *(0.3440894)^{2} * 250}{2 * 0.3440894 \mathrm{e}^{2 * 0.3440894\left(\mathrm{~h}_{0}+1.166\right)}-2 * 0.3440894} \\
& =8.591602, \\
\mathrm{~h}_{2} & =7.254729, \\
\mathrm{~h}_{3} & =6.089752, \\
\mathrm{~h}_{4} & =5.273459, \\
\mathrm{~h}_{5} & =4.933119, \\
\mathrm{~h}_{6} & =4.885745, \\
\mathrm{~h}_{7} & =\mathrm{h}_{6}-\frac{\mathrm{e}^{2 * 0.3440894\left(\mathrm{~h}_{6}+1.166\right)}-2 * 0.3440894\left(\mathrm{~h}_{6}+1.166\right)-1-2 *(0.3440894)^{2} * 250}{2 * 0.3440894 \mathrm{e}^{2 * 0.3440894\left(\mathrm{~h}_{6}+1.166\right)}-2 * 0.3440894} . \\
& =4.884944 .
\end{aligned}
$$

Now $\left(\left|h_{7}-h_{6}\right|<0.005\right)$, so $h=4.884944$.

By equation (11), we compute successive value of $c_{i}+$ starting with $c_{1}+=0$ 
International Journal of Mathematical, Engineering and Management Sciences

Vol. 4, No. 5, 1277-1286, 2019

https://dx.doi.org/10.33889/IJMEMS.2019.4.5-101

$$
\begin{aligned}
& \mathrm{C}_{\mathrm{i}}+=\max \left[0, \mathrm{x}_{\mathrm{i}}^{0.27777}-\left(0.9011057 *(1)^{0.27777}+0.3440894 * 0.2780203 *(1)^{0.27777}\right)\right. \\
& \left.+\mathrm{C}_{\mathrm{i}-1}+\right] \text {, } \\
& \mathrm{C}_{\mathrm{i}}+=\max \left[0, \mathrm{x}_{\mathrm{i}}^{0.27777}-0.9967695+\mathrm{C}_{\mathrm{i}-1}+\right] \text {. }
\end{aligned}
$$

Thus if $\mathrm{C}_{\mathrm{i}}+>4.884944 * 0.2780203(1)^{0.27777}=1.358113$, the Control chart will signal out of control.

A plot of the Combined Shewhart-CUSUM control scheme based on the transformed observations which approximately normal distribution by putting the power $\mathrm{p}=0.27777$ on exponential distributed random variable, with the upper CUSUM limit of 1.358113 and Shewhart limit of 1.735167, is shown in Figure 1. It can be seen, the CUSUM chart signals a change with the $87^{\text {th }}$ cumulative sum breaching the control limit while the sample point lies outside the Shewhart limit at $80^{\text {th }}$ point. Thus, Combined Shewhart-CUSUM control scheme is appropriate to quickly detect small as well as large shift in the process.

Table 1. Exponential distributed simulated observations in which the first 70 observations have mean of 1 and the remaining 30 observations have a mean of 2 .

\begin{tabular}{|c|c|c|c|c|c|c|c|}
\hline S. No. & Observations & S. No. & Observations & S. No. & Observations & S. No. & Observations \\
\hline 1 & 1.275012 & 26 & 0.323179 & 51 & 3.780650 & 76 & 2.740157 \\
\hline 2 & 1.839189 & 27 & 1.541008 & 52 & 1.828259 & 77 & 0.031402 \\
\hline 3 & 1.684099 & 28 & 0.729656 & 53 & 0.943600 & 78 & 2.594180 \\
\hline 4 & 0.273658 & 29 & 0.452781 & 54 & 0.861949 & 79 & 4.766397 \\
\hline 5 & 1.287355 & 30 & 4.530053 & 55 & 0.570235 & 80 & 9.284280 \\
\hline 6 & 0.433465 & 31 & 0.013239 & 56 & 1.104272 & 81 & 3.565475 \\
\hline 7 & 0.416178 & 32 & 0.622854 & 57 & 0.990773 & 82 & 5.576569 \\
\hline 8 & 0.414192 & 33 & 0.039747 & 58 & 0.091323 & 83 & 7.845603 \\
\hline 9 & 1.165529 & 34 & 0.038283 & 59 & 1.229389 & 84 & 0.648795 \\
\hline 10 & 0.027285 & 35 & 0.052568 & 60 & 0.095926 & 85 & 3.326990 \\
\hline 11 & 3.387107 & 36 & 1.085602 & 61 & 1.450531 & 86 & 2.047517 \\
\hline 12 & 3.048128 & 37 & 1.170370 & 62 & 0.385312 & 87 & 5.995597 \\
\hline 13 & 0.341408 & 38 & 1.793508 & 63 & 0.712849 & 88 & 7.175860 \\
\hline 14 & 0.469469 & 39 & 0.405439 & 64 & 1.194387 & 89 & 5.914588 \\
\hline 15 & 0.391657 & 40 & 0.269010 & 65 & 0.933852 & 90 & 1.697418 \\
\hline 16 & 0.155340 & 41 & 2.337722 & 66 & 0.557122 & 91 & 1.100326 \\
\hline 17 & 0.651664 & 42 & 5.252697 & 67 & 1.975667 & 92 & 5.967013 \\
\hline 18 & 0.331198 & 43 & 1.456239 & 68 & 1.614779 & 93 & 0.491090 \\
\hline 19 & 0.435458 & 44 & 0.736100 & 69 & 1.244741 & 94 & 1.240761 \\
\hline 20 & 1.736889 & 45 & 1.183378 & 70 & 0.392422 & 95 & 1.710645 \\
\hline 21 & 0.283764 & 46 & 0.290360 & 71 & 0.569076 & 96 & 1.559848 \\
\hline 22 & 0.792379 & 47 & 0.734786 & 72 & 0.882317 & 97 & 0.346583 \\
\hline 23 & 1.267773 & 48 & 0.529566 & 73 & 3.045051 & 98 & 2.259329 \\
\hline 24 & 2.565313 & 49 & 0.360139 & 74 & 1.238553 & 99 & 4.476474 \\
\hline 25 & 1.252512 & 50 & 1.171523 & 75 & 1.550555 & 100 & 6.689868 \\
\hline
\end{tabular}


International Journal of Mathematical, Engineering and Management Sciences

Vol. 4, No. 5, 1277-1286, 2019

https://dx.doi.org/10.33889/IJMEMS.2019.4.5-101

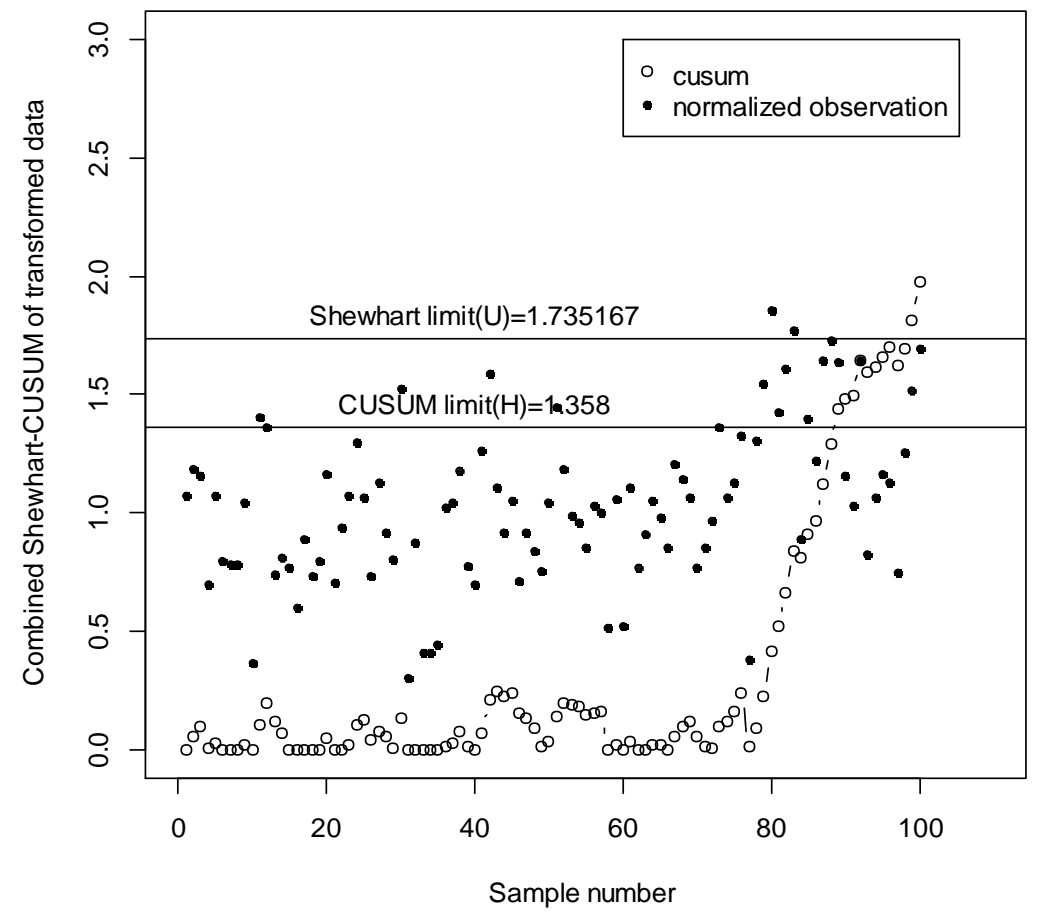

Figure 1. Combined Shewhart-CUSUM chart for transformed exponentially distributed data with $\mathrm{ARL}=250$

\section{Calculation of ARL with Monte Carlo Simulation}

The Statistical performance of a control chart shall be measured by the ARL. The run length is a random variable that denotes the number of points required before an out of control signal is shown by the chart. The ARL is the expected value of the run length. It measures on an average how much points the chart takes to detect the shift in the process. The ARL for without shift in the process is called in-control ARL. A well-designed control chart should offer large ARL value when there is no change in the process and small ARL value when there is shift/ change in the process.

To study the performance of the proposed Combined Shewhart-CUSUM Scheme for the exponential variable, we provide the approximate value of ARL for the pre-specified shift. The proposed Combined Shewhart-CUSUM Scheme is based on certain approximations, so we have used Monte Carlo simulation to compute the ARL associated with particular parameters. ARL calculated for the proposed chart is based on 1,00,0000 simulated observations. We estimated the values of ARLs to monitor the process from the in control mean $\mu_{0}=1$ to out of control mean $\mu_{1}=2$, based on in control ARL of 200, 350 and 500 and shown in Table 2.

A CUSUM chart with a small value of $\mathrm{K}$ is sensitive to small shifts. A CUSUM chart becomes less sensitive to small shifts but more sensitive to larger shifts as $\mathrm{K}$ increases. This can be explained by the fact that a CUSUM chart will stay inactive (i.e. $C_{i}+=0$ ) as long as the shift is less than K. Thus, a CUSUM chart with a large $\mathrm{K}$ value is insensitive to small shifts. The Shewhart chart, which based its decision on the most recent sample mean, is the CUSUM chart with the largest possible value of $\mathrm{K}$ for a fixed in-control ARL and is thus the most sensitive for 
International Journal of Mathematical, Engineering and Management Sciences

Vol. 4, No. 5, 1277-1286, 2019

https://dx.doi.org/10.33889/IJMEMS.2019.4.5-101

detecting the very large shift. In order to investigate the performance of the proposed Combined Shewhart-CUSUM Scheme to detect the shift of different magnitude, that means for varying out of control mean $\left(\mu_{1}\right)$ for fixed in control mean $\left(\mu_{0}\right)$ and in control ARL (ARL $)$ the reference value $\mathrm{k}$, decision interval $\mathrm{h}$, out of control ARL has been calculated and shown in Table 3 . For all numerical computations, the programs have been developed in R-software.

Table 2. Simulated ARLs for the combined Shewhart-CUSUM scheme for normalized exponentially distributed data where $\mu_{0}=1$ to $\mu_{1}=2$

\begin{tabular}{|c|c|c|c|}
\hline \multirow{3}{*}{ True Mean $(\boldsymbol{\mu})$} & $\mathbf{A R L}_{\mathbf{0}}=\mathbf{2 0 0}$ & $\mathbf{A R L}_{\mathbf{0}}=\mathbf{3 5 0}$ & $\mathbf{A R L}_{\mathbf{0}}=\mathbf{5 0 0}$ \\
\cline { 2 - 4 } & $\mathbf{k}=\mathbf{0 . 3 4 4 0 7 9}$ & $\mathbf{k}=\mathbf{0 . 3 4 4 0 7 9}$ & $\mathbf{k}=\mathbf{0 . 3 4 4 0 7 9}$ \\
\hline & $\mathbf{h}=\mathbf{1 . 2 7 4 4 1 6}$ & $\mathbf{h}=\mathbf{1 . 5 7 8 6 2 2}$ & 492.368300 \\
\hline 1.00 & 199.856100 & 349.454900 & 202.069200 \\
\hline 1.10 & 113.199200 & 156.081700 & 105.033200 \\
\hline 1.20 & 56.657220 & 85.437950 & 63.673180 \\
\hline 1.30 & 39.184950 & 53.445640 & 42.994110 \\
\hline 1.40 & 27.670170 & 37.306750 & 31.678450 \\
\hline 1.50 & 21.505380 & 27.913940 & 24.645600 \\
\hline 1.60 & 17.400380 & 22.131040 & 20.124040 \\
\hline 1.70 & 14.845610 & 18.208570 & 16.884930 \\
\hline 1.80 & 12.686010 & 15.424290 & 14.515300 \\
\hline 1.90 & 11.178060 & 13.352600 & 12.733790 \\
\hline 2.00 & 9.977252 & 11.789510 & 10.228780 \\
\hline 2.10 & 9.021281 & 10.552930 & 9.315567 \\
\hline 2.20 & 8.259616 & 9.549402 & 8.561996 \\
\hline 2.30 & 7.571054 & 8.726689 & 7.911180 \\
\hline 2.40 & 7.025975 & 8.027473 & 7.362393 \\
\hline 2.50 & 6.551105 & 7.453631 & 6.903369 \\
\hline 2.60 & 6.160556 & 6.964632 & 6.476466 \\
\hline 2.70 & 5.810406 & 6.528293 & 6.116792 \\
\hline 2.80 & 5.476181 & 6.150455 & 5.791904 \\
\hline 2.90 & 5.210151 & 5.819380 & \\
\hline 3.00 & 4.961351 & 5.523995 & \\
\hline & & & \\
\hline
\end{tabular}

Table 3. Combined Shewhart- CUSUM scheme parameters and out of control ARLs with the varying value of out of control mean when target mean $\mu_{0}=1$

\begin{tabular}{|c|l|l|l|l|l|l|l|l|l|}
\hline & \multicolumn{3}{|c|}{$\mathbf{A R L}_{\mathbf{0}}=\mathbf{2 0 0}$} & \multicolumn{3}{c|}{$\mathbf{A R L}_{\mathbf{0}}=\mathbf{3 5 0}$} & \multicolumn{3}{c|}{$\mathbf{A R L}_{\mathbf{0}}=\mathbf{5 0 0}$} \\
\hline $\boldsymbol{\mu}_{\mathbf{1}}$ & $\mathbf{k}$ & $\mathbf{h}$ & $\mathbf{\mathbf { A R L } _ { \mathbf { 1 } }}$ & $\mathbf{k}$ & $\mathbf{h}$ & $\mathbf{A R L}_{\mathbf{1}}$ & $\mathbf{k}$ & $\mathbf{h}$ & $\mathbf{A R L}_{\mathbf{1}}$ \\
\hline 1.1 & 0.0435 & 3.1367 & 95.5602 & 0.0435 & 4.1996 & 139.2952 & 0.0435 & 5.0183 & 171.9395 \\
\hline 1.2 & 0.0842 & 2.6513 & 57.2856 & 0.0842 & 3.4181 & 77.4894 & 0.0842 & 3.9766 & 91.4746 \\
\hline 1.3 & 0.1225 & 2.3141 & 39.3413 & 0.1225 & 2.9144 & 50.5669 & 0.1225 & 3.3389 & 58.3444 \\
\hline 1.4 & 0.1588 & 2.0655 & 29.1966 & 0.1588 & 2.5608 & 36.4620 & 0.1588 & 2.9050 & 41.2514 \\
\hline 1.5 & 0.1932 & 1.8739 & 22.9030 & 0.1932 & 2.2975 & 27.8895 & 0.1932 & 2.5886 & 31.2727 \\
\hline 1.6 & 0.2260 & 1.7213 & 18.5867 & 0.2260 & 2.0928 & 22.2823 & 0.2260 & 2.3463 & 24.6580 \\
\hline 1.7 & 0.2574 & 1.5964 & 15.5416 & 0.2574 & 1.9286 & 18.3691 & 0.2574 & 2.1539 & 20.2032 \\
\hline 1.8 & 0.2874 & 1.4920 & 13.3379 & 0.2874 & 1.7934 & 15.5850 & 0.2874 & 1.9970 & 16.9678 \\
\hline 1.9 & 0.3163 & 1.4033 & 11.6415 & 0.3163 & 1.6799 & 13.4499 & 0.3163 & 1.8661 & 14.6133 \\
\hline 2.0 & 0.3441 & 1.3267 & 10.3127 & 0.3441 & 1.5829 & 11.8008 & 0.3441 & 1.7550 & 12.7516 \\
\hline 2.1 & 0.3709 & 1.2599 & 9.2248 & 0.3709 & 1.4991 & 10.5000 & 0.3709 & 1.6594 & 11.2728 \\
\hline 2.2 & 0.3968 & 1.2010 & 8.3584 & 0.3968 & 1.4257 & 9.4611 & 0.3968 & 1.5760 & 10.1208 \\
\hline 2.3 & 0.4219 & 1.1485 & 7.6561 & 0.4219 & 1.3607 & 8.5935 & 0.4219 & 1.5025 & 9.1795 \\
\hline 2.4 & 0.4461 & 1.1015 & 7.0507 & 0.4461 & 1.3028 & 7.8843 & 0.4461 & 1.4372 & 8.3893 \\
\hline 2.5 & 0.4697 & 1.0590 & 6.5453 & 0.4697 & 1.2508 & 7.2691 & 0.4697 & 1.3787 & 7.7265 \\
\hline
\end{tabular}


International Journal of Mathematical, Engineering and Management Sciences

Vol. 4, No. 5, 1277-1286, 2019

https://dx.doi.org/10.33889/IJMEMS.2019.4.5-101

\section{Conclusion}

In this paper, we provide the properties of the Combined Shewhart-CUSUM control scheme for exponentially distributed data. The simulated value of ARL shows that after transformation of the data into normal approximation and adding Shewhart control limits to existing CUSUM control Chart improves ARL in compare to existing charts. The proposed scheme is more effective than the Shewhart and CUSUM chart individually in detecting smaller, moderate and large changes in process quality characteristics. The out-of-control ARL values are provided at various shifts and various in-control ARL for the proposed Combined Shewhart-CUSUM scheme. The frequency of false alarm is higher for the smaller value of in-control ARL and more observations are required to detect the shift in the process if higher in-control ARL is selected therefore Quality control practitioner has to select the parameters of the scheme after considering the false alarm cost as well as the cost of defective production carefully. If a company is already using CUSUM control charts to monitor normally distributed data then it is not hard to implement the proposed scheme. Scheme parameters (value of $\mathrm{k}$ and $\mathrm{h}$ ) and out of control ARL to detect $\delta$ standard deviation shifts are provided in Table 4 , where $\delta=0.01,0.02,0.03 \ldots \ldots \ldots . . .$. , and in-control ARL values are 200, 350 and 500, which may be helpful to the quality control practitioners in designing the Combined Shewhart-CUSUM when data is highly skewed according to the required efficiency of the process. If we use traditional charts for heavy tails distributed observations then false alarms are more than expected.

Table 4. Combined Shewhart-CUSUM scheme parameters and out of control ARL to detect $\delta$ standard deviation shift.

\begin{tabular}{|c|c|c|c|c|c|c|c|c|c|}
\hline & \multicolumn{3}{|c|}{$\mathrm{ARL}_{0}=200$} & \multicolumn{3}{|c|}{$\mathrm{ARL}_{0}=350$} & \multicolumn{3}{|c|}{$\mathrm{ARL}_{0}=500$} \\
\hline$\delta$ & $K$ & h & $\mathbf{A R L}_{1}$ & $\mathbf{k}$ & h & $\mathbf{A R L}_{1}$ & $\mathbf{k}$ & h & $\mathbf{A R L}_{1}$ \\
\hline 0.1 & 0.0435 & 3.2571 & 99.4293 & 0.0435 & 4.1996 & 137.7145 & 0.0435 & 4.9617 & 170.4245 \\
\hline 0.2 & 0.0842 & 2.7408 & 59.5500 & 0.0842 & 3.4181 & 77.7037 & 0.0842 & 3.9388 & 90.4675 \\
\hline 0.3 & 0.1225 & 2.3853 & 40.7438 & 0.1225 & 2.9144 & 50.9580 & 0.1225 & 3.3104 & 57.7267 \\
\hline 0.4 & 0.1588 & 2.1249 & 30.1127 & 0.1588 & 2.5608 & 36.4323 & 0.1588 & 2.8821 & 40.9529 \\
\hline 0.5 & 0.1932 & 1.9251 & 23.4759 & 0.1932 & 2.2975 & 27.8805 & 0.1932 & 2.5692 & 30.9173 \\
\hline 0.6 & 0.2260 & 1.7664 & 19.0841 & 0.2260 & 2.0928 & 22.2638 & 0.2260 & 2.3295 & 24.4584 \\
\hline 0.7 & 0.2574 & 1.6369 & 15.8800 & 0.2574 & 1.9286 & 18.4261 & 0.2574 & 2.1390 & 20.0585 \\
\hline 0.8 & 0.2874 & 1.5288 & 13.6215 & 0.2874 & 1.7934 & 15.6189 & 0.2874 & 1.9835 & 16.9201 \\
\hline 0.9 & 0.3163 & 1.4371 & 11.8836 & 0.3163 & 1.6799 & 13.4546 & 0.3163 & 1.8538 & 14.4911 \\
\hline 1.0 & 0.3441 & 1.3581 & 10.4948 & 0.3441 & 1.5829 & 11.8051 & 0.3441 & 1.7437 & 12.6652 \\
\hline 1.1 & 0.3709 & 1.2893 & 9.3984 & 0.3709 & 1.4991 & 10.5125 & 0.3709 & 1.6488 & 11.2464 \\
\hline 1.2 & 0.3968 & 1.2286 & 8.5175 & 0.3968 & 1.4257 & 9.4447 & 0.3968 & 1.5661 & 10.0765 \\
\hline 1.3 & 0.4219 & 1.1746 & 7.7876 & 0.4219 & 1.3607 & 8.6060 & 0.4219 & 1.4932 & 9.1420 \\
\hline 1.4 & 0.4461 & 1.1263 & 7.1533 & 0.4461 & 1.3028 & 7.8783 & 0.4461 & 1.4284 & 8.3452 \\
\hline 1.5 & 0.4697 & 1.0827 & 6.6388 & 0.4697 & 1.2508 & 7.2684 & 0.4697 & 1.3703 & 7.6919 \\
\hline 1.6 & 0.4926 & 1.0431 & 6.1823 & 0.4926 & 1.2038 & 6.7626 & 0.4926 & 1.3179 & 7.1225 \\
\hline 1.7 & 0.5149 & 1.0069 & 5.8123 & 0.5149 & 1.1610 & 6.3090 & 0.5149 & 1.2704 & 6.6521 \\
\hline 1.8 & 0.5366 & 0.9737 & 5.4766 & 0.5366 & 1.1219 & 5.9308 & 0.5366 & 1.2270 & 6.2187 \\
\hline 1.9 & 0.5577 & 0.9432 & 5.1995 & 0.5577 & 1.0860 & 5.5823 & 0.5577 & 1.1872 & 5.8549 \\
\hline 2.0 & 0.5783 & 0.9149 & 4.9401 & 0.5783 & 1.0528 & 5.2991 & 0.5783 & 1.1505 & 5.5387 \\
\hline
\end{tabular}

\section{Conflict of Interest}

The authors confirm that there is no conflict of interest to declare for this publication. 
International Journal of Mathematical, Engineering and Management Sciences

Vol. 4, No. 5, 1277-1286, 2019

https://dx.doi.org/10.33889/IJMEMS.2019.4.5-101

\section{Acknowledgment}

The author would like to express his sincere thanks to the referees for their valuable suggestions towards the improvement of the paper. The author is also grateful to Prof. Bhupendra Singh, Department of Statistics, C. C. S. University, Meerut for continuous guidance and University Grants Commission, Government of India for financial support for the work.

\section{References}

Alwan, L.C. (2000). Designing an effective exponential CUSUM chart without the use of nomographs. Communication in Statistics: Theory and Methods, 29(12), 2879-2894.

Chan, L.Y., Xie, M., \& Goh, T.N. (2000). Cumulative quantity control charts for monitoring production processes. International Journal of Production Research, 38(2), 397-408.

Duncan, A.J. (1986). Quality control and industrial statistics. 5th. Ed. Irwin, Homewood, IL: Richard D Irvin.

Gan, F.F. (1994). Design of optimal exponential CUSUM control charts. Journal of Quality Technology, 26(2), 109- 124.

Hawkins, D.M. (1992). Evaluation of the average run lengths of cumulative sum charts for an arbitrary data distribution. Communications in Statistics-Simulation and Computation, 21(4), 1001-1020.

Kittlitz, R.G. (1999). Transforming the exponential for SPC applications. Journal of Quality Technology, 31(3), 301-308.

Liu, J.Y., Xie, M., \& Goh, T.N. (2006). CUSUM chart with transformed exponential data. Communications in Statistics - Theory and Methods, 35(10), 1829-1843

Lucas, J.M. (1982). Combined Shewhart-CUSUM quality control schemes. Journal of Quality Technology $14(2), 51-59$.

Lucas, J.M. (1985). Counted data CUSUMs. Technometrics, 27(2), 129-144.

Lucas, J.M., \& Crosier, R.B (1982). Fast initial response for CUSUM quality control schemes: give your CUSUM a head start. Technometrics, 24(3), 199-205.

Montgomery, D.C. (2018). Introduction to statistical quality control. (6 $6^{\text {th }}$ ed.). John Wiley and Sons, Inc.

Nelson, L.S. (1994). A control chart for parts-per-million nonconforming items. Journal of Quality Technology, 26(3), 239-240.

Page, E.S. (1954). Continuous inspection schemes. Biometrika, 41(1/2), 100-115.

Siegmund, D. (1985). Sequential analysis: test and confidence intervals. Springer-Verlag, New York.

Tyagi, D. (2014). On some problems in engineering statistics. Ph.D. Thesis, C.C.S. University, Meerut, India.

Vardeman, S., \& Ray, D. (1985). Average run lengths for CUSUM schemes when observations are exponentially distributed. Technometrics, 27(2), 145-150.

Woodall, W.H., \& Adams, B.M. (1993). The statistical design of CUSUM charts. Quality Engineering, $5(4), 559-570$ 